\title{
Het beoordelen van professioneel gedrag bij studenten en artsen
}

\author{
S.J. van Luijk, M. van Santen-Hoeufft, H.F.P. Hillen, J.G.E. Smeets
}

\section{Samenvatting}

In binnen- en buitenland staat professioneel gedrag van studenten en artsen in toenemende mate in de belangstelling. Een van de redenen hiervoor is dat studenten en arts-assistenten soms vastlopen op een laat tijdstip in de opleiding, wat het bieden van begeleiding bemoeilijkt of zelfs onmogelijk maakt. Daarnaast is er een toenemend aantal klachten tegen medische beroepsbeoefenaars, met name op het communicatieve vlak. De indruk bestaat dat de afgelopen jaren binnen medische curricula en opleidingen mogelijk te veel nadruk gelegd is op het meten van alleen kennis en vaardigheden. Hierdoor blijven enkele andere belangrijke facetten van de beroepsuitoefening, met name aspecten van professioneel gedrag, onderbelicht. Dit artikel gaat in op de betekenis en de inhoud van professioneel gedrag. Ook aandachtspunten bij de beoordeling van professioneel gedrag komen uitvoerig aan bod. Er wordt een pleidooi gehouden voor expliciete aandacht voor professioneel gedrag in het opleidingstraject van student naar professional. (Luijk SJ van, Santen-Hoeufft M van, Hillen HFP, Smeets JGE. Het beoordelen van professioneel gedrag bij studenten en artsen. Tijdschrift voor Medisch Onderwijs 2000;19(5): 163-171.)

\section{Inleiding}

De samenleving verwacht van een arts meer dan alleen kennis en medisch-technische vaardigheden. ${ }^{1-6}$ Een arts moet kunnen functioneren als professional. Dit vereist daarbij passend gedrag, zoals het goed kunnen omgaan met patiënten, collegae en andere hulpverleners. Ook de wijze waarop wordt omgegaan met stress, het stellen van eigen grenzen en het zelfstandig kunnen functioneren zijn belangrijk. Uit gegevens over klachten van patiënten over artsen blijkt dat een groot deel van de klachten betrekking heeft op bejegening en communicatie. ${ }^{7-12}$ Ook zijn er klachten van patiënten die het gevolg zijn van een slechte samenwerking tussen artsen. Tussen artsen onderling zijn er in de praktijk problemen die te maken hebben met tekortkomingen in professioneel gedrag. Zo is het erg moeilijk fouten te bespreken en/of collegae aan te spreken op onprofessioneel gedrag. ${ }^{13} 14$ Men is niet gewend kritiek te geven en te ontvangen en ziet dit soms als bedreigend en als een vorm van disloyaliteit. Als toekomstige doktoren al in de basisopleiding vaardigheden als zelfreflectie, het geven en ontvangen van feedback en communiceren met patiënten en collegae leren, kan dit bijdragen aan een meer 'open cultuur', waar uiteindelijk patiënt en dokter beter van worden.

Tot nu toe is er in de basisartsopleiding en in de vervolgopleidingen slechts beperkt aandacht geweest voor professioneel gedrag. 1516 In de preklinische fase van de basisartsopleiding komt een klein deel van de vaardigheden die hiervoor nodig zijn aan bod in het vaardigheidsonderwijs. ${ }^{17} \mathrm{Er}$ is echter geen sprake van systematische beoordeling van deze vaardigheden. Hierdoor worden studenten niet gestimuleerd om deze vaardigheden toe te passen. Zij zijn dan ook wat professioneel gedrag betreft onvoldoende voor- 
bereid op de co-assistentschappen, wat bijdraagt aan de cultuurschok die veel studenten ervaren bij de start van de klinische fase. Hoewel de meeste studenten de overgang van preklinische naar klinische fase 'overleven', zijn er ook studenten die behoefte hebben aan meer begeleiding, onder meer op het punt van professioneel gedrag. ${ }^{18-23}$ Voor een enkele student is zelfs deze begeleiding ontoereikend en soms moet het staken van de studie serieus overwogen worden. ${ }^{24} 25$ Voor de betrokken student en docenten zijn dergelijke overwegingen, zo laat in het opleidingstraject, traumatisch. Vanuit het oogpunt van de opleiding moet dan ook het streven zijn om dit te voorkomen. Aandacht voor professioneel gedrag in de preklinische fase kan leiden tot meer zelfvertrouwen en zelfstandigheid bij studenten, hetgeen de overstap naar de patiëntenzorg makkelijker maakt. ${ }^{26}$ In tegenstelling tot studenten worden artsassistenten in opleiding wel regelmatig geëvalueerd op een aantal aspecten van professioneel gedrag. Deze beoordelingen behoren jaarlijks plaats te vinden in een gesprek tussen opleider en arts-assistent aan de hand van een beoordelingsformulier. In het eerste jaar van de opleiding dient een dergelijke evaluatie zelfs viermaal plaats te vinden. Artsen die hun vervolgopleiding hebben voltooid worden niet systematisch beoordeeld op hun professioneel gedrag. Pas bij disfunctioneren speelt de sociale controle en medical audit een rol. Maar dan is het eigenlijk al te laat. Er had reeds voor het manifeste disfunctioneren een gesprek met de betrokken arts plaats moeten vinden op basis van eerder geregistreerde signalen.

Vaardigheden die bijdragen tot adequaat professioneel gedrag, moeten deel uitmaken van het basiscurriculum en de vervolgopleidingen. Dit betekent uiteraard ook dat professioneel gedrag getoetst moet worden. In dit artikel wordt het begrip professioneel gedrag nader omschreven en wordt ingegaan op de beoordeling van professioneel gedrag in de diverse fasen van de medische opleidingen.

\section{Wat is professioneel gedrag?}

In het Raamplan 1994 artsopleiding en het eindrapport van de Interfacultaire Commissie Richtlijnen Artsexamen (ICRA) wordt niet gesproken over professioneel gedrag maar over attitude. ${ }^{1} 2$ Attitude is echter een breed begrip, dat zowel een binnen- als een buitenkant kent. De binnenkant wordt gevormd door waarden en normen, de buitenkant door het gedrag dat daaruit voortkomt. ${ }^{27}$ Professioneel gedrag heeft betrekking op de buitenkant van attitude. Gedrag kan omschreven worden, waardoor er leerdoelen met bijbehorende toetsinstrumenten ontwikkeld kunnen worden. Belangrijke kenmerken van professioneel gedrag zijn het goed kunnen omgaan met patiënten, andere hulpverleners en collegae, het kunnen omgaan met stress, het kunnen stellen van eigen grenzen en zelfstandig kunnen functioneren. Hieraan ligt een aantal vaardigheden ten grondslag, zoals communicatievaardigheden, presentatievaardigheden, werken in teamverband, omgaan met kritiek, het geven van feedback, stressmanagement, time management en reflecteren op het eigen functioneren.

\section{Het beoordelen van professioneel gedrag}

Bij het beoordelen van professioneel gedrag gaat het dus alleen om het zichtbare deel van attitude, het objectiveerbare gedrag. Professioneel gedrag kan globaal geoperationaliseerd worden aan de hand van de volgende inhoudelijke categorieën: het omgaan met taken, de communicatie met anderen en het omgaan met zichzelf. ${ }^{28-32}$ Deze categorieën kunnen uitge- 
werkt worden in een beoordelingsinstrument. Omdat validiteit, betrouwbaarheid en acceptabiliteit belangrijke aspecten zijn bij beoordeling, zal eerst ingaan worden op deze aspecten van het beoordelen van professionele vaardigheden. Vervolgens wordt een beoordelingsinstrument besproken en tenslotte worden de mogelijke consequenties van een onvoldoende beoordeling voor betrokkenen aan de orde gesteld.

\section{Validiteit}

Een belangrijk aspect bij de beoordeling is de validiteit van het oordeel. Het beoordelen van professioneel gedrag stelt eisen aan de beoordelingslijst, de beoordelaar en de beoordelingssituatie. ${ }^{28}$ Voor de beoordelingslijst is inhoudsvaliditeit een voorwaarde. Dit kan bereikt worden door toekomstige beoordelaars zo veel mogelijk te betrekken bij het vaststellen van de criteria. Tevens kan gebruik gemaakt worden van ervaringen elders. Na gebruik in de praktijk kunnen psychometrische gegevens gebruikt worden om de beoordelingslijst te verbeteren.

De situatie waarin de beoordeling dient plaats te vinden is ook van belang voor de validiteit. Beoordeling kan het beste plaatsvinden in een situatie die zo veel mogelijk overeenkomt met de latere beroepspraktijk. Dus voor de beginnende student geneeskunde zijn de stages in de gezondheidszorg of onderwijssituaties waarin geoefend wordt met echte of gesimuleerde patiënten, goede beoordelingssituaties. In het begin van de studie zijn er in veel curricula niet zo veel van dergelijke situaties. Het is echter ook mogelijk om in de onderwijssituatie elementen van professioneel gedrag te beoordelen, die informatief zijn voor het toekomstig functioneren van de student. Voor de arts-assistent lijken het functioneren op de zaal en de patiëntenbesprekingen een meer adequate setting voor beoordeling dan de polikliniek, omdat daar - tot nu toe - minder natuurlijke observatiemogelijkheden zijn.

\section{Betrouwbaarheid}

Er wordt beweerd dat het beoordelen van professioneel gedrag subjectief en dus onbetrouwbaar is. Voor een eenmalig oordeel van één beoordelaar geldt dit ook. Vele subjectieve oordelen, gedurende langere tijd, door verschillende beoordelaars, op basis van observaties, kunnen gezamenlijk wel een objectief beeld geven van betrokkene.

Het aanbrengen van structuur in de beoordelingssituatie bijvoorbeeld door (deels) dezelfde punten in de beoordeling te betrekken, zal in positieve zin bijdragen aan de vergelijkbaarheid van de oordelen van verschillende docenten/opleiders.

\section{Acceptabiliteit}

Voor een succesvolle implementatie van een beoordelingssysteem is het noodzakelijk dat docenten/opleiders en andere betrokkenen (studenten, arts-assistenten, staf) goed op de hoogte zijn van de procedures rond de beoordeling, het doel van de beoordeling, de manier waarop deze doelen worden geoperationaliseerd, welke plaats uitkomsten van metingen innemen in het scala van beoordelingen die over betrokkenen worden verzameld en wat er precies van betrokkenen zelf wordt verwacht. Er moet tijd gereserveerd worden om de beoordelingen met elkaar te bespreken. Dit is belangrijk omdat de nabespreking zelf een onderwijsmoment is en bovendien informatie kan verschaffen over het professionele gedrag van betrokkenen in de zin van feedback geven en ontvangen. Een belangrijke praktische consequentie van het beoordelen is dat er goede afspraken gemaakt moeten worden over de registratie, het beheer van en toegang tot de geregistreerde gegevens. 
Professioneel gedrag wordt door velen gezien als een belangrijk element van de medische beroepsbeoefening. Wanneer men er in slaagt de beoordeling zo goed mogelijk te integreren in de dagelijkse onderwijspraktijk of praktijk van de gezond- heidszorg zal dit zeker ten goede komen aan de acceptatie. Primair dient in dit opzicht voortgebouwd te worden op bestaande structuren van individuele beoordeling en begeleiding die, waar nodig, aangepast of uitgebouwd kunnen worden.

Figuur 1. Beoordeling professioneel gedrag voor arts-assistenten.

Naam arts-assistent

Naam beoordelaar:

Afdeling

Beoordelingssituatie:

\section{Omgaan met taken}

Omgaan met beschikbare tijd

onproductief - efficiënt

Opstelling in het werk

slordig - punctueel

Zelfstandigheid

heeft voortdurend hulp nodig - kan goed zelfstandig werken

Zelfvertrouwen

zeer onzeker/te zeker van zichzelf — straalt zelfvertrouwen uit

\section{Niet}

Adequaat (*)

Datum:

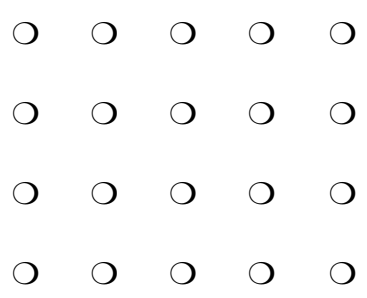

\section{Communicatieve aspecten}

Houding

star - flexibel

Samenwerking

solistisch - coöperatief

Collegiaal gedrag

niet geïntegreerd binnen groep — goed geïntegreerd binnen groep

Omgang met patiënten/anderen

afstandelijk - betrokken

Communicatie met patienten/anderen

onduidelijk, bot - helder, empatisch

\section{Het eigen functioneren}

Omgaan met kritiek van anderen

gesloten opstelling - open opstelling

Geven van/vragen om feedback

aanvallend - opbouwend

Vermogen tot zelfanalyse

geen zelfinzicht - kritisch zelfoordeel

Op tijd verschijnen/Niet verschijnen

te laat of niet komen - komt op tijd
Adequaat

$\left(^{*}\right)$ Indien oordeel niet-adequaat: geef toelichting $\rightarrow$ 
Figuur 1 (vervolg). Toelichting bij de niet adequaat beoordeelde items.

Toelichting bij de niet adequaat beoordeelde items:

Adviezen voor de arts-assistent/Afspraken:

Voor gezien:

Naam arts-assistent:

Naam beoordelaar:

Handtekening:

Handtekening:

\section{Beoordelingsinstrument}

De eerder genoemde categorieën: omgaan met taken, communicatieve aspecten en het eigen functioneren kunnen in meer gedetailleerde criteria uitgewerkt worden, toegespitst op de specifieke situatie waarin professioneel gedrag gemeten wordt. In figuur 1 wordt een voorbeeld weergegeven van een beoordelingsformulier voor de beoordeling van de arts-assistent.
Bij de ontwikkeling van de criteria is ervan uitgegaan dat kennis, medisch-technische vaardigheden en wetenschappelijke kwaliteiten al op een andere wijze worden beoordeeld. In de toelichting bij het beoordelingsformulier zijn de criteria uitgewerkt voor de situatie van de arts-assistent. 
Figuur 2. Toelichting beoordeling professioneel gedrag voor arts-assistenten.

\section{Omgaan met taken}

Omgaan met beschikbare tijd

De arts-assistent plant taken op efficiënte wijze en weet spreekuren binnen de gestelde tijd af te ronden. Er is een goede (tijd)balans tussen de verschillende werkzaamheden.

Opstelling in het werk

In contacten met patiënten, in het werk; hoe gaat de arts-assistent om met opgedragen taken, houden van presentaties, patiëntenbesprekingen, ontslagbrieven? Slordig, laks of juist erg consciëntieus. Hoe is de benadering van (patiënten)problemen, systematisch of ongericht?

Zelfstandigheid

Het zonder (al te veel) bijsturing kunnen afhandelen van een consult en opdrachten. Overleg met de achterwacht alleen bij geïndiceerde casuïstiek.

Zelfvertrouwen

Hoe komt een arts-assistent over tijdens discussies, patiëntenbesprekingen, presentaties (gespannen, onzeker)?

\section{Communicatieve aspecten}

Houding

De flexibiliteit in het gedrag van een arts-assistent ten opzichte van collegae, studenten, staf en patiënten.

Samenwerking

Solistisch is zichzelf bedoeld of onbedoeld te vaak buiten de groep plaatsen. Gericht op anderen wil zeggen kan in de professionele setting goed samenwerken met andere collegae en stafleden.

Collegiaal gedrag

Het investeren van tijd binnen de professionele setting in contacten met verpleegkundigen, assistenten, artsen en anderen; het overnemen van taken van anderen, het nemen van verantwoordelijkheid in samenwerkingsrelaties.

Omgang met patiënten/anderen

Staat open voor behoeften en verwachtingen van patiënten en anderen; kan zich inleven in de patiënt.

Communicatie met patiënten/anderen

Adequate gevoelsreflecties worden op de juiste momenten gegeven, het overbrengen van informatie wordt met tact en empathie gedaan in bewoordingen die een patiënt begrijpt. Kan eigen grenzen stellen in het contact met patiënten. Zal als professional nooit primair reageren, bijvoorbeeld bij conflicten.

\section{Het eigen functioneren}

Omgaan met kritiek van anderen

Staat open voor kritiek, reageert open op kritiek, kritiek leidt tot een verandering van het gedrag.

Geven van en vragen om feedback

Het gaat hier m.n. om de vorm van feedback.

Vermogen tot zelfanalyse

Zomaar wat zeggen zonder het (zeker) te weten, verwoorden van eigen sterke en zwakke punten, formuleren van eigen leerdoelen.

Op tijd verschijnen/niet verschijnen

Op tijd zijn op de afdeling, bij patiënten of zonder geldige reden niet verschijnen op afspraken. 
Voor studenten kan een vergelijkbaar beoordelingsformulier gebruikt worden, waarin de uitwerking van de criteria is aangepast aan de eisen ten aanzien van professioneel gedrag die voor studenten gelden. ${ }^{28}$ Beoordelingscriteria voor professioneel gedrag moeten duidelijk gerelateerd zijn aan de hoofdtaken van het individu in een bepaalde opleidings- of werksituatie.

\section{Sanctionering}

Het regelmatig beoordelen van professioneel gedrag binnen een opleidingssituatie heeft naast het onderwijseffect het voordeel dat vroegtijdig personen met onprofessioneel gedrag worden gesignaleerd. Dit betreft waarschijnlijk een zeer kleine groep betrokkenen. In het algemeen gaat men ervan uit dat het ongeveer $1 \%$ van de studenten en specialisten betreft. ${ }^{33-35} \mathrm{Er}$ worden echter ook veel hogere percentages beschreven. ${ }^{36}$ Signalering van onprofessioneel gedrag hoeft niet onmiddellijk te leiden tot sancties. Het belangrijkste bij het vaststellen van onprofessioneel gedrag is dat bepaalde zwakke punten van betrokkenen door anderen worden gesignaleerd en dat er afspraken gemaakt worden hoe daarmee om te gaan. Het gaat in eerste instantie om leren en verbeteren en dus 'groeien' in het professionele gedrag. Wanneer geen verbetering optreedt, zullen er op den duur wel sanctionerende maatregelen genomen moeten worden door de examencommissie, de opleider of collega's in de praktijk. Het eerste summatieve moment moet gepland worden voordat betrokkenen structureel in de praktijk van de gezondheidszorg werkzaam zijn, dus in het basiscurriculum en nadat er voldoende onafhankelijke beoordelingsmomenten hebben plaatsgevonden. Afhankelijk van de opbouw van het curriculum en het studiejaar waarin de beoordelingen beginnen, zal dit uiterlijk rond het vierde studiejaar moeten gebeuren. Een tweede summatief beoordelingsmoment is zinvol als de student één jaar in de praktijk van de gezondheidszorg heeft gewerkt met een beperkte verantwoordelijkheid en zelfstandigheid. Een derde beoordelingsmoment kan plaatsvinden als een arts-assistent een jaar lang volledig 'zelfstandig' gewerkt heeft. Vaak is de arts dan als agnio werkzaam.

De arts-assistent in opleiding heeft nog eens vier beoordelingsmomenten in het eerste jaar om, mits zorgvuldig uitgevoerd, genoeg feedback te kunnen krijgen. Vanzelfsprekend dient dit hele evaluatietraject goed gereguleerd, gereglementeerd en geregistreerd te worden omdat het tot verstrekkende maatregelen kan leiden.

\section{Begeleiding}

Voor betrokkenen die één of meer onvoldoende beoordelingen hebben gekregen inzake het professioneel gedrag, dient begeleiding te worden aangeboden. Voor studenten zou dat de taak van de studieadviseur kunnen zijn, die afhankelijk van het soort probleem kan doorverwijzen. Voor arts-assistenten zijn begeleidingsmogelijkheden tot op heden minder gestructureerd en duidelijk. Als er al sprake is van begeleiding wordt deze vaak gegeven door stafleden die direct of indirect invloed kunnen uitoefenen op de beoordeling van de arts-assistent. Geen ideale situatie voor een vertrouwensrelatie, die onontbeerlijk is voor de begeleiding. Zeker in gevallen waarbij langdurige en intensieve begeleiding verwacht wordt, verdient het aanbeveling een niet bij de beoordeling betrokken staflid te benoemen, die deskundig en ervaren is in het begeleiden van artsen in een opleidingssituatie. 


\section{Conclusie}

Meer dan vroeger worden eisen gesteld aan het professionele gedrag van (toekomstige) artsen. Bij docenten en opleiders groeit de opvatting dat het beoordelen van kennis en vaardigheden niet voldoende is voor het verkrijgen van het artsexamen of inschrijving in het specialistenregister. Het moet vanzelfsprekend worden dat in de opleiding tot arts en specialist systematisch aandacht wordt besteed aan de vaardigheden die ten grondslag liggen aan het professionele gedrag. De bewustwording en signalering van alle aspecten van professioneel gedrag moet zo vroeg mogelijk in de opleiding beginnen. Dan kan ook in een vroeg stadium gewerkt worden aan zwakke punten en kan feedback gegeven worden over de vorderingen. Tot nu toe beperken evaluaties zich veelal tot een functioneringsoordeel waarbij de kwaliteit van de feedback veelal afhankelijk is van de tijd en de interesse die de opleider ervoor heeft. Dergelijke oordelen vinden meestal voor het eerst plaats tijdens de co-schappen. Om de groei van de betrokkene te kunnen beoordelen is het van belang om de gegevens longitudinaal te verzamelen. Het beoordelen van deze competentie vergt tijd en inspanning, en soms ook een cultuurverandering bij de bestaande staf. Echter het belang om professioneel gedrag te bespreken en te beoordelen is omgekeerd evenredig aan de mate waarin dat nu in de praktijk gebeurt. Het wordt hoog tijd dat daarin verandering komt.

\section{Literatuur}

1. Metz JCM, Pels Rijcken-Van Erp Taalman Kip EH, Van den Brand-Valkenburg BWM. Raamplan 1994 artsopleiding. Nijmegen: Universitair Publikatiebureau Katholieke Universiteit Nijmegen; 1994.

2. Metz JCM, Stoelinga GBA, Vleuten CPM van der, Jacobs JCG, redactie. Het artsexamen: voorstellen voor landelijke richtlijnen. Eindrapport van de
Interfacultaire Commissie Richtlijnen Artsexamen (ICRA). Nijmegen: Universitair Publikatiebureau Katholieke Universiteit Nijmegen; 1996.

3. Handleiding met betrekking tot de reglementen en voorschriften ter zake van de erkenning en registratie van medisch specialisten. Uittreksel besluiten Centraal College voor de Erkenning en Registratie van Medische Specialisten. Utrecht; 1990.

4. Handleiding met betrekking tot de reglementen en voorschriften ter zake van de erkenning en registratie van medisch specialisten. Uittreksel besluiten Centraal College voor de Erkenning en Registratie van Medische Specialisten. Algemene eisen, aanvullende bepalingen. Utrecht; 1992.

5. Good medical practice. General Medical Council. July, 1998.

6. Project Professionalism. American Board of Internal Medicine. Philadelphia PA; 1995.

7. Staat van de gezondheidszorg; een rapportage over kwaliteit en toegankelijkheid in de zorg. Zoetermeer: Staatstoezicht Volksgezondheid, Ministerie van Volksgezondheid, Welzijn en Sport; 1997. p. 228.

8. Klachten, klachtbehandeling en rapportage over klachten (Nivel). Utrecht: Post; 1995. p. 43.

9. Mace SE. An analysis of patient complaints in an observation unit. Journal of Quality in Clinical Practice 1998;18:151-8.

10. Lim HC, Tan CB, Goh LG, Ling SL. Why do patients complain? A primary health care study. Singapore Medical Journal 1998;39:390-5.

11. Mulholland J, Dawson KP. Can we make it better? Journal of Quality in Clinical Practice 1998;18: 217-20.

12. Pitchert JW, Miller CS, Hollo AH, Gauld-Jaeger J, Federspiel CF, Hicson GB. What health professionals can do to identify and resolve patient dissatisfaction. Journal of Quality Improvement 1998; 24:303-12.

13. Rosenthal MM, Mulcahy L, Lloyd-Bostock S. Medical mishaps, pieces of the puzzle. Buckingham, Philadelphia: Open University Press; 1999.

14. Rosenthal MM. The incompetent doctor, behind closed doors. Buckingham, Philadelphia: Open University Press; 1995.

15. Ludmerer KM. Instilling professionalism in medical education. JAMA 1999;282:881-2.

16. Swick HM, Szenas P, Danoff D, Whitcomb ME. Teaching professionalism in undergraduate medical education. JAMA 1999;282:830-2.

17. Scherpbier AJJA. Kwaliteit van vaardigheidsonderwijs gemeten [dissertatie]. Maastricht: Universitaire Pers Maastricht; 1997.

18. Michie S, Sandhy S. Stress management for clinical medical students. Med Educ 1994;28:528-33.

19. Guthrie EA, Black D, Shaw CM, Hamilton J, Creed FH, Tomenson B. Psychological stress in 
medical students: a comparison of two very different university courses. Stress Medicine 1997;13: 179-84.

20. Wolf TM. Stress, coping and health: enhancing well-being during medical school. Med Educ 1994;28:8-17.

21. Williams S, Dale J, Glucksman E, Wellesley A. Senior house officers' work related stressors, psychological distress, and confidence in performing clinical tasks in accident and emergency: a questionnaire study. BMJ 1997;314:713-8.

22. Helmers KF, Danoff D, Steinert Y, Leyton M, Young SN. Stress and depressed mood in medical students, law students and graduate students at McGill University. Acad Med 1997;8:708-14.

23. Papadakis MA, Osborn EHS, Cooke M, Healy K. A strategy for the detection and evaluation of unprofessional behavior in medical students. Acad Med 1999;74(9):980-9.

24. Cate ThJ ten, Hulst MLM van der. Geschiktheidsbeoordeling in de opleiding tot arts: aspecten van reglementering. Bulletin Medisch Onderwijs 1999;18:1-8.

25. Haes JCJM, Hoos AM, Cate ThJ ten, Regt HB. Geschiktheid voor het medisch beroep: ontwikkeling van een instrument. In: Spaai GWG, Verweij AMJJ, Remmen R, Dolmans DHJM, Denekens JPM, Smal JA, Albersnagel EPL, Dikkers JH, redactie. Gezond Onderwijs-8. Houten/Diegem: Bohn Stafleu Van Loghum; 1998.p.380-1.

26. Markakis KM, Beckman HB, Suchman AL, Franker RM. The path to professionalism: cultivating humanistic values and attitudes in residency training. Acad Med 2000;2:141-9.

27. Batenburg V. Medical students' attitudes. Attitude development in a medical school [dissertatie]. Utrecht: Rijksuniversiteit Utrecht; 1997.

28. Luijk SJ van, Smeets JGE, Smits JFM, Wolfhagen HAP, Perquin MLF. Beoordeling en begeleiding van professioneel gedrag tijdens de opleiding geneeskunde. Bulletin Medisch Onderwijs 1999;18 :58-65.
29. Irvine D. The performance of doctors: the new professionalism. Lancet 1999;353:1174-7.

30. Irvine D. The performance of doctors. II Maintaining good practice, protecting patients from poor performance. BMJ 1997;314:613-5.

31. Harden RM. Early postgraduate education and the strategy of the dolphins. Med Teach 1999;21: 365-8.

32. Epstein RM. Mindful practice. JAMA 1999;282: 833-9.

33. Interne rapportage Project Studieadvisering. Maastricht: Universiteit Maastricht; 1999.

34. Lens $P$, Wal $G$ van der. Een onderzoek naar disfunctioneren van specialisten. Ned Tijdschr Geneeskd 1994;138:1127-31.

35. Kahn PS. Veel ziekenhuizen kampen met disfunctionerende specialisten. Medisch Contact 1999;54:1640-2.

36. Srinivasan M. Medical professionalism: more than simply a job. JAMA 1999;282:814.

De auteurs:

Dr. S.J. van Luijk, arts en studieadviseur, Capaciteitsgroep Onderwijsontwikkeling en Onderwijsresearch, Universiteit Maastricht.

Drs. M. van Santen-Hoeufft, reumatologe, Capaciteitsgroep Interne Geneeskunde, Academisch Ziekenhuis Maastricht.

Prof. dr. H.F.P. Hillen, internist en opleider, voorzitter van de Capaciteitsgroep Interne Geneeskunde, Academisch Ziekenhuis Maastricht.

Drs. J.G.E. Smeets, student-assistent, Capaciteitsgroep Onderwijsontwikkeling en Onderwijsresearch, Universiteit Maastricht.

Correspondentieadres:

Dr. S.J. van Luijk, Capaciteitsgroep Onderwijsontwikkeling en Onderwijsresearch, Universiteit Maastricht, Postbus 616, 6200 MD Maastricht, s.vanluijk@educ.unimaas.nl.

\section{Summary}

The aim of the practitioner to put patients first has important consequences for medical education. Knowledge and medical technical skills do not suffice to meet the needs of society and the standards of the profession. Attention should also be focussed on how professionals deal with work and others, and reflect on their own performance. The profession should place more emphasis on these aspects of the professional behaviour of students, residents, and staff. This means that professional behaviour should be incorporated in medical training programmes and assessed. This should be programmed from the earliest possible phase of the training programme to enable timely detection of problems and intervention. Feedback and, if needed, guidance should be given to students about their progress in professional behaviour. This should be done within a framework of regular meetings concerning individual performance. It takes time to implement such an assessment system. However, the importance of professional behaviour being inversely proportionate to the attention it is currently receiving in medical education, the time for change is now. (Luijk SJ van, Santen-Hoeufft M van, Hillen HFP, Smeets JGE. Assessment of professional behaviour in medical training. Dutch Journal of Medical Education 2000;19(5): 163-171.) 